\title{
Haemolytic uraemic syndrome associated with non shiga toxin-producing Escherichia coli bacteraemia: a case report
}

\author{
Stéphane Bally ${ }^{1 *}$ D, Jacques Fourcade ${ }^{1}$ and Véronique Frémeaux-Bacchi ${ }^{2}$
}

\begin{abstract}
Background: Haemolytic uraemic syndrome (HUS) is a thrombotic microangiopathy (TMA) characterized by predominant renal involvement. Several types of HUS can be distinguished: the most frequent «typical » HUS, due to shiga toxin producing Escherichia coli (STEC), "atypical" HUS due to complement alternative pathway dysregulation and "secondary" HUS associated with various diseases/conditions, the classification of which is still subject to debate.

Case presentation: We report a case of HUS following E.coli prostatitis and bacteraemia in an adult male. He presented with severe renal and neurological involvement. Initially considered as a "typical" HUS, the condition was treated by antibiotics. No other specific treatment for HUS was administered. The outcome was favorable. We eventually identified a non shiga toxin producing E.coli. Genetic testing of the complement alternative pathway revealed a rare - potentially pathogenic - variant of factor $\mathrm{H}$. This constitutes a possible factor of susceptibility for atypical HUS, suggesting that E.coli infection may be the trigger.
\end{abstract}

Conclusion: This case raises the question of complement exploration for HUS associated with infections, in order to classify such cases of HUS in accordance with their underlying pathophysiological mechanisms.

Keywords: Complement variant, Escherichia coli, Hemolytic uremic syndrome, Infection

\section{Background}

Thrombotic microangiopathies (TMA) are rare disorders characterized by an initial endothelial cell injury, and by the triad of mechanical haemolytic anaemia, thrombocytopenia and ischemic organ injury. Haemolytic uraemic syndrome (HUS) is a TMA characterized by predominant renal involvement and normal ADAMTS13 activity (>10\%), which excludes thrombotic thrombocytopenic purpura (TTP).

There are several types of HUS and their classification evolves with elucidation of their underlying pathophysiological mechanisms: 1) Infection-related HUS, mainly « typical » HUS following intestinal infection due to shiga toxin-producing Escherichia coli (STEC), which is the most frequent form. Other infections, such as Streptococccus pneumoniae, Influenza A, HIV, are involved

\footnotetext{
* Correspondence: stephane.bally@ch-metropole-savoie.fr

${ }^{1}$ Service de Néphrologie Dialyse, Centre Hospitalier Métropole Savoie, Place

Lucien Biset, BP 31125, 73011 Chambery, Cedex, France

Full list of author information is available at the end of the article
}

more rarely. 2) Atypical HUS (aHUS), due to an acquired (auto-antibodies) or a constitutional dysregulation of complement alternative pathway, which is found in more than $60 \%$ of cases. 3) Secondary HUS, alongside coexisting diseases or conditions: drugs, malignancies, autoimmune diseases, pregnancy. 4) Other rare genetic forms of HUS are due to Cobalamin $\mathrm{C}$ and diacylglycerol kinase $\varepsilon$ deficiencies. In $30 \%$ of cases the mechanism is unknown.

STEC-HUS and aHUS account for $85-90$ and 5\% respectively of cases of HUS in children. Their respective frequency is not well documented in adults $[1,2]$.

Typical HUS usually follows a STEC intestinal infection, identified via stool cultures, polymerase chain reaction (PCR) for Stx genes encoding for shiga toxins, or detection of anti-lipopolysaccharide (LPS) antibodies in serum.

The genetics of « atypical » complement-HUS is complex. Rare or common variants with established or highly probable functional consequences are a risk factor for developing the disease. Pathogenic variants have 
been identified in more than $60 \%$ of cases in one of the 8 genes encoding for C3 and factor B forming alternative C3 convertase, or for one of the 3 regulating proteins (factor H, factor I and MCP, Membrane Cofactor Protein or CD46) and in CFHR5, DGKe or the gene of thrombomodulin. Common variants in $\mathrm{FH}$ and MCP genes increase the risk of developing the disease by 2 to 5 times. In most cases, a trigger is necessary to initiate the disease.

We report a case of HUS in an adult male, following non STEC E.coli prostatitis and bacteraemia. Genetic testing of the complement alternative pathway revealed a rare variant of factor $\mathrm{H}$.

\section{Case presentation}

A 58-year-old man was hospitalized for haemorrhoid surgery. His medical history featured only hypercholesterolaemia.

On day 1 after surgery, he developed fever and symptoms of prostatitis, with no digestive symptoms. Following blood and urine cultures, antibiotherapy (ofloxacin and gentamycin) was initiated. Platelet count was $100 \mathrm{G} / \mathrm{L}$ (normal before surgery), haemoglobin $(\mathrm{Hb})$ was normal $(14.5 \mathrm{~g} / \mathrm{dL})$. Renal function was normal (serum creatinine $=1.02 \mathrm{mg} / \mathrm{dL}$ ).

Urine and blood cultures came back positive for Escherichia coli and ofloxacin was continued. No E.coli was found in the stools (culture and PCR).

On day 4, platelet count decreased to $27 \mathrm{G} / \mathrm{L}$, without anaemia, and creatinine rose to $1.75 \mathrm{mg} / \mathrm{dL}$, but the patient had urinary retention.

Day 6, although the infection was under control and the patient had remained haemodynamically stable throughout (blood pressure 120/62 mmHg), he developed acute kidney injury (AKI) with anuria (creatinine = $7.36 \mathrm{mg} / \mathrm{dL}$ ) and neurological signs which included confusion, hallucinations, anterograde amnesia, static cerebellar syndrome and transient motor deficit of the left lower limb. The renal CT-scan was normal, as was cerebral magnetic resonance imaging (MRI). Laboratory tests showed: $\mathrm{Hb}=11.8 \mathrm{~g} / \mathrm{dL}$, haptoglobin $=1.53 \mathrm{~g} / \mathrm{L}, \mathrm{LDH}=$ $2615 \mathrm{U} / \mathrm{L}$ (upper limit $480 \mathrm{U} / \mathrm{L}$ ), platelet count $=61 \mathrm{G} / \mathrm{L}$.

This renal and neurological presentation was initially attributed to sepsis and possible drug toxicity (antibiotics). Haemodialysis was started and antibiotherapy modified to ceftriaxone.

On days 9-12, the patient's neurological state worsened: he presented seizures, controlled using anti epileptic treatment. The spinal tap was normal. At this point $\mathrm{Hb}$ had dropped to $8 \mathrm{~g} / \mathrm{dL}$, LDH remained elevated $(1265 \mathrm{U} / \mathrm{L})$ and schistocytes 3\% were detected. Platelet count, however, normalized ( $250 \mathrm{G} / \mathrm{L})$. ADAMTS13 activity was normal (38\%, with FRETS-VWF73 technique), thus excluding a diagnosis of TTP. Antinuclear antibodies and ANCA were negative.

A hypothesis of HUS associated with "non-intestinal" STEC infection was made.

An initial complement work-up revealed no abnormalities (Table 1).

A kidney biopsy, performed on day 15 , confirmed the diagnosis of HUS. Light microscopy showed 13 permeable glomeruli with endothelial cell swelling, widening of the subendothelial space, and double contours of the glomerular basement membrane. Fibrin and platelet thrombi were observed in glomerular capillaries. Images of regenerating tubular necrosis were also observed. An immunofluorescence study revealed no significant immune deposits (Fig. 1).

Haemolysis subsequently disappeared and the patient's neurological state improved. Although urine output increased, the patient remained on dialysis.

While waiting to identify the type of $E$. coli involved, we were unable to exclude a diagnosis of non-intestinal STEC-HUS. In view of the favorable outcome, the patient did not receive any plasmatherapy, or complement inhibitor. However, we were able to discontinue dialysis after 1 month as renal function improved.

When testing for anti-LPS antibodies in serum was repeated 3 weeks after disease onset, no E.coli typically associated with HUS in France was found (detection of IgM and IgA ('line-blot') anti-LPS antibodies in the

Table 1 Complement testing

\begin{tabular}{lll}
\hline Protein and technique & Result & Normal range \\
\hline CH50 (hemolytic assay) & $136 \%$ & $70-130$ \\
C3 antigen (nephelometry) & $1430 \mathrm{mg} / \mathrm{L}$ & $660-1250$ \\
C4 antigen (nephelometry) & $283 \mathrm{mg} / \mathrm{L}$ & $93-380$ \\
Factor B antigen (nephelometry) & $195 \mathrm{mg} / \mathrm{L}$ & $90-320$ \\
Factor H antigen (ELISA) & $149 \%$ & $65-140$ \\
Anti-factor H antibodies (isotype IgG) (ELISA) & negative \\
Factor I antigen (ELISA) & $137 \%$ & $70-130$ \\
Membrane expression of CD46 (MCP) at the surface of granulocytes CD33+ (Beckman Coulter cytometer, type Navios) & 18.8 & $13.0-19.0$ \\
\hline
\end{tabular}




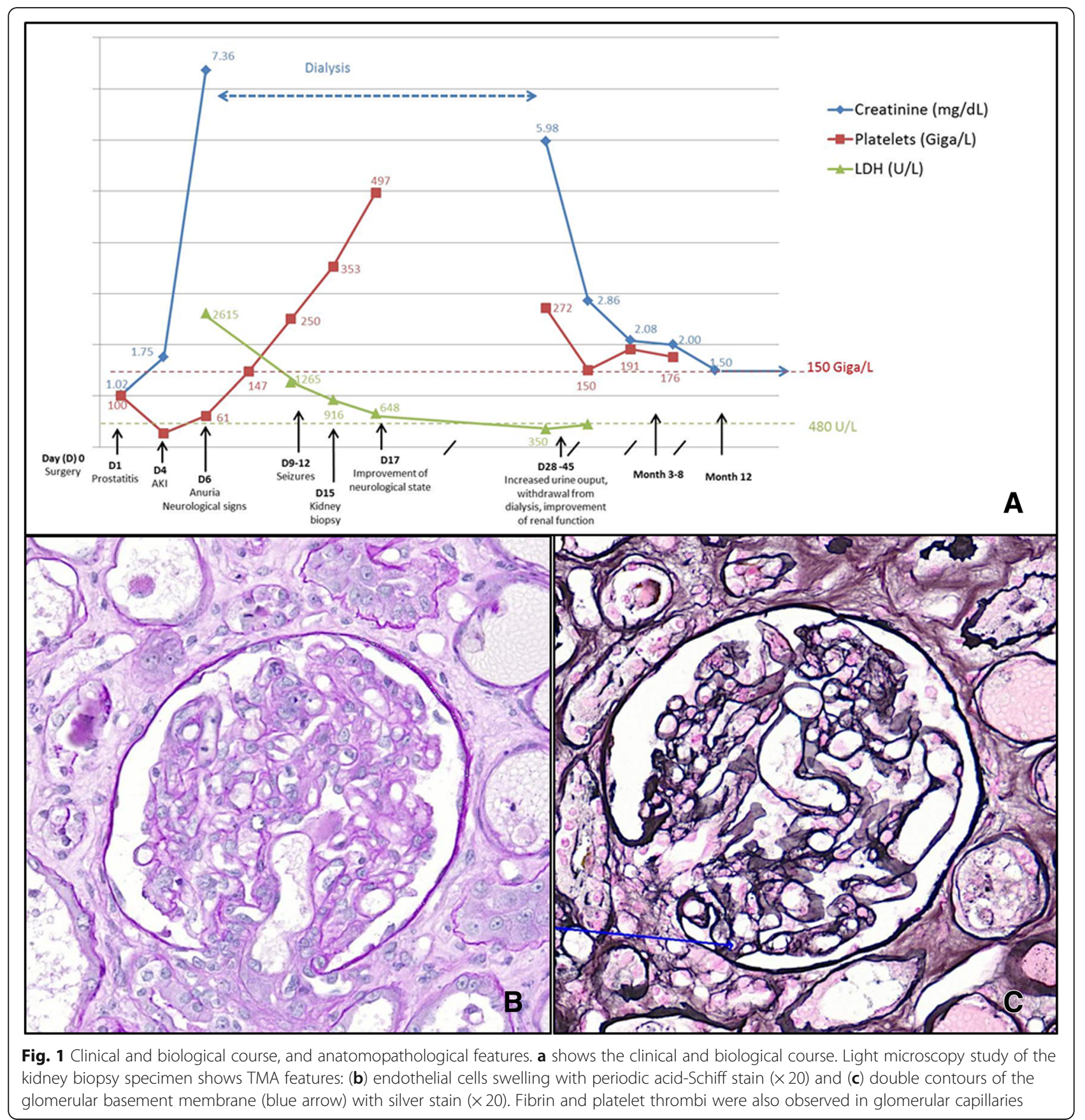

serum, for serogroups O26, O55, O91, O103, O111, O128, O145, O157). Moreover, screening for virulence factors of the E.coli found in blood cultures came back negative (stx 1 and stx 2 gene amplification negative; eae and $e h x A$ gene amplification negative; fyuA, hlyC, sfal foc, papC, iucC, papGIII, cnfl, papGII, iroN, vat, clbB genes negative).

After 3 months, serum creatinine was $2 \mathrm{mg} / \mathrm{dL}$ and proteinuria was $0.4 \mathrm{~g} /$ day. After 1 year, serum creatinine remained stable at $1.5 \mathrm{mg} / \mathrm{dl}$, with normal blood pressure and clinical state. No recurrence has been observed over a 3 year period.

Screening for rare variants in complement alternative pathway genes was performed (Technique: EUrenOmics NGS panel) and showed the presence of a heterozygous variant in the gene encoding complement factor $\mathrm{H}$ (p.Val215Ile; c.643 G > A). This variant is located in the N-terminal domain of the protein (SCR4) and is not present in the ExAc data base (http://exac.broadinstitute.org/). 


\section{Discussion and conclusions}

We describe a case of HUS associated with an E.coli bacteraemia with a urinary starting point, without diarrhea and without the presence of E.coli in the stools. This clinical presentation is rare, although cases of "typical "STEC-HUS without diarrhea - in particular cases associated with acute pyelonephritis and sometimes bacteraemia - have been reported [35]. However, in this case, E.coli was not a STEC. Testing for anti-LPS antibodies did not identify any E.coli typically associated with HUS in France. That was not enough to exclude certain emerging serotypes such as O104:H4 or O80:H2, which can be responsible for similar clinical presentations [6]. But further testing for shigatoxines Stx1 and Stx2 (PCR) and screening for any other virulence factor of the E.coli found in the blood cultures were negative.

A transient activation of complement is observed in patients with STEC-HUS $[7,8]$. Some of them carry genetic factors of susceptibility for aHUS, supporting the hypothesis of a multiple-hit model, with infection playing the role of trigger, on the grounds of genetic predisposition $[9,10]$.

In our case, we hypothesize that the non shiga toxin-producing E.coli sepsis was the trigger for HUS.

An extensive biochemical complement analysis proved normal (Table 1). This type of finding has been reported in number of aHUS cohorts. In the French Cohort, C3 level is lower in only $40 \%$ of cases. Almost half of pathogenic variants have functional consequences, which have no impact on antigenic levels. So this does not exclude the diagnosis $[11,12]$.

We finally carried out screening of complement alternative pathway genes, and this revealed a heterozygous variant in the gene encoding complement factor $\mathrm{H}$ (p.Val215Ile; c.643 G > A). Factor $\mathrm{H}(\mathrm{FH})$ is the key regulator of the alternative pathway (AP). The $\mathrm{CFH}$ variant located in SCR4 of the protein is not present in the large cohort of healthy donors. This suggests a frequency of under $0.001 \%$. Its pathogenicity has not been reported. The SCR $1-4$ region is the only $\mathrm{C} 3 \mathrm{~b}$ binding site which acts as a cofactor for FI to cleave $\mathrm{C} 3 \mathrm{~b}$ and as an accelerant of AP C3-convertase decay. In this respect, the CFH variant p.Val215Ile may impair complement regulatory activity on surfaces. However the functional implications of the $\mathrm{CFH}$ variant warrant further investigation but could explain this serious presentation of non STEC-HUS.

Clinical outcome was finally favorable without complement blockade, with a residual mild chronic kidney disease. However the presence of a complement gene variant prompts us to maintain regular monitoring, particularly during periods of infection, in order to detect any recurrence of HUS rapidly.
This case raises the question of complement testing in patients with infection related-HUS. There is little data in the literature regarding the existence of genetic factors of susceptibility in cases such as these. Interactions between infection and HUS are dual. On the one hand, infection on its own can induce endothelial injury and complement activation, leading to TMA. On the other hand, infection - like other conditions such as pregnancy - can be a trigger for aHUS in susceptible patients [11-13]. So, it has been demonstrated that cases of pregnancy related-HUS share the same genetic factors of predisposition as so-called 'primary' aHUS; pregnancy is therefore considered to be a trigger for aHUS [14].

This issue is important because in the first case HUS will normally not recur, whereas in cases of genetic predisposition, HUS may do so.

Further studies assessing the implications of complement dysregulation in infection-related HUS are, consequently, warranted.

\section{Abbreviations}

aHUS: Atypical haemolytic uraemic syndrome; AKI: Acute kidney injury; AP: Alternative pathway; CFH: Complement factor $\mathrm{H}$; $\mathrm{CFI}$ : Complement factor I; G: Giga; Hb: Haemoglobin; HUS: Haemolytic uraemic syndrome; L: Liter; LPS: Lipopolysaccharide; MRI: Magnetic resonance imaging; PCR: Polymerase chain reaction; STEC: Shiga toxin-producing Escherichia coli; TMA: Thrombotic microangiopathy; TTP: Thrombotic thrombocytopenic purpura

\section{Acknowledgements}

We thank Catherine Dal Molin for her valuable help with reading the manuscript and advice on the writing.

\section{Funding}

no funding.

Availability of data and materials

All data are included in this published article.

Authors' contributions

SB collected the data and wrote the case report. JF made substantial contributions to the conception and the revision of the manuscript. VF-B performed the genetic screening, and contributed to the conception and revision of the manuscript. All authors read and approved the final manuscript.

\section{Ethics approval and consent to participate} N/A

\section{Consent for publication}

Written informed consent was obtained from the patient for publication of this Case Report and any accompanying images. A copy of the written consent is available for review by the Editor of this journal.

\section{Competing interests}

SB serves as principal investigator of Alexion M11-001 atypical Haemolytic Uraemic Syndrome international registry and served on teaching courses for Alexion Pharmaceuticals. JF serves as co-investigator of Alexion M11-001 atypical Haemolytic Uraemic Syndrome international registry. VF-B served on advisory boards and in teaching courses for Alexion Pharmaceuticals and serves as coordinator of the scientific advisory board of Alexion M11-001 atypical Haemolytic Uraemic Syndrome international registry.

\section{Publisher's Note}

Springer Nature remains neutral with regard to jurisdictional claims in published maps and institutional affiliations. 


\section{Author details}

'Service de Néphrologie Dialyse, Centre Hospitalier Métropole Savoie, Place Lucien Biset, BP 31125, 73011 Chambery, Cedex, France. ${ }^{2}$ Service d'Immunologie Biologique, Hôpital Européen Georges Pompidou (AP-HP), 20 rue Leblanc, 75908 Paris, Cedex 15, France.

Received: 17 April 2018 Accepted: 25 April 2019

Published online: 07 May 2019

\section{References}

1. Loirat C, Fakhouri F, Ariceta G, Besbas N, Bitzan M, Bjerre A, et al. An international consensus approach to the management of atypical hemolytic uremic syndrome in children. Pediatr Nephrol. 2016;31(1):15-39.

2. Fakhouri F, Zuber J, Fremeaux-Bacchi V, Loirat C. Haemolytic uraemic syndrome. Lancet. 2017;390(10095):681-96.

3. Chiurchiu C, Firrincieli A, Santostefano M, Fusaroli M, Remuzzi G, Ruggenenti P. Adult nondiarrhea hemolytic uremic syndrome associated with Shiga toxin Escherichia coli 0157:H7 bacteremia and urinary tract infection. Am J Kidney Dis. 2003:41(1):E4.

4. Nguyen QV, Hochstrasser L, Chuard C, Hachler H, Regamey C, Descombes E. Adult hemolytic-uremic syndrome associated with urosepsis due to Shigatoxin-producing Escherichia coli 0138:H. Ren Fail. 2007;29(6):747-50.

5. Toval F, Schiller R, Meisen I, Putze J, Kouzel IU, Zhang W, et al. Characterization of urinary tract infection-associated Shiga toxin-producing Escherichia coli. Infect Immun. 2014;82(11):4631-42.

6. Soysal N, Mariani-Kurkdjian P, Smail Y, Liguori S, Gouali M, Loukiadis E, et al. Enterohemorrhagic Escherichia coli hybrid Pathotype 080:H2 as a new therapeutic challenge. Emerg Infect Dis. 2016;22(9):1604-12.

7. Ferraris JR, Ferraris V, Acquier AB, Sorroche PB, Saez MS, Ginaca A, et al. Activation of the alternative pathway of complement during the acute phase of typical haemolytic uraemic syndrome. Clin Exp Immunol. 2015; 181(1):118-25.

8. Stahl AL, Sartz L, Karpman D. Complement activation on platelet-leukocyte complexes and microparticles in enterohemorrhagic Escherichia coliinduced hemolytic uremic syndrome. Blood. 2011;117(20):5503-13.

9. Ahlenstiel-Grunow T, Hachmeister S, Bange FC, Wehling C, Kirschfink M, Bergmann C, et al. Systemic complement activation and complement gene analysis in enterohaemorrhagic Escherichia coli-associated paediatric haemolytic uraemic syndrome. Nephrol Dial Transplant. 2016:31(7):1114-21.

10. Alberti M, Valoti E, Piras R, Bresin E, Galbusera M, Tripodo C, et al. Two patients with history of STEC-HUS, posttransplant recurrence and complement gene mutations. Am J Transplant. 2013;13(8):2201-6.

11. Fremeaux-Bacchi V, Fakhouri F, Garnier A, Bienaime F, Dragon-Durey MA, Ngo S, et al. Genetics and outcome of atypical hemolytic uremic syndrome: a nationwide French series comparing children and adults. Clin J Am Soc Nephrol. 2013;8(4):554-62.

12. Noris M, Caprioli J, Bresin E, Mossali C, Pianetti G, Gamba S, et al. Relative role of genetic complement abnormalities in sporadic and familial aHUS and their impact on clinical phenotype. Clin J Am Soc Nephrol. 2010;5(10): 1844-59.

13. Kavanagh D, Goodship TH, Richards A. Atypical hemolytic uremic syndrome. Semin Nephrol. 2013;33(6):508-30.

14. Fakhouri F, Roumenina L, Provot F, Sallee M, Caillard S, Couzi L, et al. Pregnancy-associated hemolytic uremic syndrome revisited in the era of complement gene mutations. J Am Soc Nephrol. 2010;21(5):859-67.

Ready to submit your research? Choose BMC and benefit from:

- fast, convenient online submission

- thorough peer review by experienced researchers in your field

- rapid publication on acceptance

- support for research data, including large and complex data types

- gold Open Access which fosters wider collaboration and increased citations

- maximum visibility for your research: over $100 \mathrm{M}$ website views per year

At BMC, research is always in progress.

Learn more biomedcentral.com/submissions 